\title{
A Study of Australian Business Excellence Award Winners
}

\author{
Maruf Hasan, Hanisah Hannifah \\ School of Mechanical and Manufacturing Engineering, The University of New South Wales, Sydney, Australia. \\ Email:m.hasan@unsw.edu.au
}

Received December $5^{\text {th }}$, 2012; revised January $10^{\text {th }}$, 2013; accepted January $21^{\text {st }}, 2013$

\begin{abstract}
The modern approach of Total Quality Management and reliability concerns excellence. Excellence in service, product, accreditation and the way the business is managed. With this approach, the services and education sectors have set new business excellence benchmarks. A study of Business Excellence award winners in Sydney and Singapore has been conducted. This paper covers the contributions of the award winning organizations in adopting the business excellence approach. The methodology comprises of a literature review of the benefits of the business excellence award and an analysis of the findings which examines the quality implemented and the result achieved by the organizations. The findings reveal that business excellence is applicable to any organization. It guides a government, private, service, education, healthcare, profit or a non-profit sector organization to organizational success. The quality approach used by the award winning organization is similar. The differences lie in the way decisions are deployed which is based on the organization's unique needs, cultures, systems and processes.
\end{abstract}

Keywords: TQM; Business Excellence; Quality; Services

\section{Introduction}

The approach to quality and its relation to organisational success is no mystery. It has been practised since World War II under the influence of famous quality gurus like W. Edwards Deming, Joseph M. Juran, Philip B. Crosby, Armand V. Feigenbaum and Kaoru Ishikawa. Business Excellence is a continuous improvement to error-free performance by everyone in an organisation so as to be the best in delivering high quality services which meet or exceed the expectation of customers. Business Excellence is adopted by Western and Asian firms as a tool to enhance international competitiveness. It ensures a firm's economic survival as the principles underlying the global Business Excellence framework builds a pathway to long term success and continuous improvement. The self assessment section of the framework highlights key areas of strength and identifies improvement in any organisation. Business Excellence is seen as an effective strategy to promote global quality awareness that countries have their own award system to recognise and reward organisations that demonstrate the highest standard of business excellence. This paper highlights that the transformation process of an organisation's culture and management system is the same for an industry in Australia or Singapore. The difference lies in the decisions made by the Senior Management Committee in implementing the transformation process which is based on the individual needs of the organisation.

\section{Literature Review}

Business Excellence is an important role in promoting and rewarding organisational excellence. Adopting the best practices of business excellence improves a nation's competitiveness which leads to a global sustainable success. Thus, receiving a business excellence award is the highest honour an organisation can attain [1].

A literature review is done on the development of the business excellence award. The first quality award that was introduced to reward organisations that demonstrates significant growth in performance is the Deming Prize. The Deming Prize was established by the Board of Directors of the Japanese Union of Scientists and Engineers (JUSE) in 1951. The improved performance in Japanese companies under the influence of quality gurus such as, Deming and Juran inspired the United States to develop the Malcolm Baldrige Award. This prestigious American quality award was named after President Reagan's Secretary of Commerce who was killed in a rodeo accident in 1987 [2]. The Malcolm Baldrige is designed to recognise American firms that practice effective quality management and make significant improvements in the quality of their goods and services. Next in line would be the European Quality Award (EQA) which was officially introduced by the European Foundation for Quality Management (EFQM). The 14 leading Western European businesses of EFQM realised that the only way to survive in the world economy was to adopt the practice of quality 
[2]. The Australian Quality Award was first established by Australian Quality Council (AQC) in 1988 and was later acquired by SAI Global (formerly known as Standards Australia International Limited) in February 2002 [2]. The Australian Quality Award seeks to increase management's quality awareness and recognises accomplishment in quality and productivity improvement. The award also provides a benchmark for their achievements among Australian organisations.

Hence, this led to a global interest in following the approach of quality. The Malcolm Baldrige framework and the Deming Prize criteria was further improved and integrated into a Business Excellence framework in the late 1990s [3].

This led to the Australian Quality Award to be renamed as the Australian Business Excellence Award. The common aim of the global business excellence award is to raise quality consciousness among industrialist and the general public, sharing of best practices and business experiences [1].

Australia is a country that is big in resources but it is geographically isolated [4]. Business Excellence has helped to narrow the distance as quality is practiced in the competitive products and services which are being exported internationally. This competitive strategy which has brought "Made in Japan" products and services from meaning cheap and unreliable to meaning quality is now widely accepted in the global competitive markets. Quality is seen as a management philosophy that drives business excellence for any organisation or industry. Australia's economy is progressing at a competitive level as more organisations embrace the practice of business excellence and its accreditation procedures as a way of doing business. A study on all Australian Stock Exchange listed as Australian Business Excellence Award Winners from 1990-2003 was conducted. This hypothetical investment concludes that award winners generate a larger return than market benchmark and continues to achieve sustainable results [5]. This just proves that business excellence pays. Recently, a literature study has been conducted which concludes that business excellence is losing its popularity. This is evident by the stabilised or declined memberships of Business Excellence foundation [6]. Australian organisations are seen to have the best practices of business excellence and the Australian Business Excellence Award is presented to organisation that demonstrates significant business improvement. The self assessment process of the Australian Business Excellence Framework measures the organisational performance thus promoting a culture of self learning, sharing of knowledge and continuous improvement. The benefits of practising the Business Excellence Framework rewards and recognises organisational performance which leads to long term benefits. The "Baldrige index" which tracks a decade performance of award winners against Standard \& Poor's 500 companies and similar study conducted in Australia reflected continuous excellence in performance among award winners. A PHD study concluded that improvement was shown in Key Performance Indicators of Australian Quality Award Winners between 1992 and 1997. A study conducted in 2000 revealed that award winners outperformed other organisations in terms of stock returns, operating income, sales and costs [7]. A desk top research method was conducted to compare national awards and it revealed the following issues. New or modified business excellence frameworks are not developed as the existing framework complies with international standards and practices so there was not a need in wasting time and effort in improving the framework. There is a lack of promotion, resource and funding by the local government and award custodian in sponsoring and supporting the Business Excellence. The lack of tools in assisting organisations in adopting the Business Excellence Framework is a rising problem. The model of Business Excellence Framework adopted by the country should be appropriate especially when it concerns the quality maturity of the business environment of that country in accessing the scores and criteria of the framework. Again, a standard model is not adopted because the model of framework practised in one country would not be effective in another country due to cultural and environmental differences. The last global issue in the research finding is that the values and principles of the national award are not aligned with the Business Excellence Framework [7]. Other factors leading to the disadvantages of the award are the amount of effort required to prepare the application form, time and financial investment involved in the process. Toyota Motor Corp. Australia Ltd., which won the Australian Quality Award in 1992 argues that it only spent around a AUD \$1000 on the whole application process whereas Xerox spent around US\$800,000 to win the Baldrige Award in 1989 [1]. This just proves that a huge financial investment is not crucial in preparing a big organisation to win a quality award. Quality should be part of the work practise environment. As in the case of Xerox, financial returns are seen by benchmarking its outstanding business practices and offering improvement programs [8]. It has been emphasised that participating in a quality award identifies improvement opportunities at the evaluation process, improves market share and profitability. There have been cases of past winners performing poorly after winning the Malcolm Baldrige Quality award such as Cadillac, Federal Express, Wallace Company and Motorola [1]. This question the long term benefits of the award. The argument put forward was that businesses are affected by economic downturn, changes in technology and fashion. It was also argued that the award focuses more on 
management and leadership processes than the actual product or service quality [2].

Marolyn Anne Bakker, ABE Manager of SAI Global commented that in Australia, past award winners have merged with stronger organisations so as to been seen as a bigger portfolio. However, it is also evident that some companies are quick to recover from the momentary period of crisis as it has better resources, superior management, leadership and business processes to guide the organisation back to the path of success [1].

\section{Analysis}

The principles of business excellence work for any kind of organisation. There is competition for customers, students, patients, resources, services and funds. Both the Singapore and Australian organisations compete for quality, reliability, price and delivery. The organisations share the same path in practising business excellence that is to stay ahead of competitors. It can be noted that the ideas of Total Quality Management are captured in the business excellence framework. The framework combines quality gurus' teachings like Crosby's 14 steps to quality improvement, Deming's 14 points of management and Juran's 10 steps to quality improvement into a single philosophy called "Business Excellence". The creation of the global Business Excellence Framework has ended the practice of awarding business on the basis of price tags. Equal opportunity is given to all organisations including non-profit organisations and the education sector to demonstrate their success. It has also been analysed that this equal opportunity just shows that organisations do not compete in business excellence for the award but to benchmark its practices, undergo the self audit review and most importantly is to identify improvement opportunities. The self-assessment section of the framework measures current progress in the organisation. It monitors the progress towards business excellence. This identifies gaps in the organisation. The self assessment results highlight the strength and improvement opportunities of the organisation. There has been a trend in the Singapore and Australian organisations to be lauded with other internal awards before these organisations were recognised with the internationally recognised, Business Excellence award. This just proves that it takes years of continuous practise, effort and improvement to achieve growth in business excellence. This practise is perfected by evaluating against the self assessment category of the Business Excellence Framework. conducted. The Australian organisations covered in this study include: Baulkham Hills Shire Council (BHSC), BizEd Services Private Limited, The Sydney Catholic Education Office, Chesalon Beecroft Aged Care Services and Water Services Division of Sydney Water Corporation. The Singapore Quality award winners are, The National
Library Board (NLB) of Singapore, The Central Provident Fund (CPF) Board and Qian Hu Corporation Limited. This paper covers the contributions of the above award winning organisations in adopting the business excellence approach.

\subsection{Leadership}

The vision, values and mission are observed as the guiding philosophy of the organisation. This philosophy creates a positive culture in the work environment. It involves the entire organisation and stakeholders in achieving the goals of the strategic planning process. All the organisations have reached success as they communicate the company purpose and goals to their employees. Business excellence is a success to these organisations because employees have a sense of ownership to the organisational values. Safety, community and environmental contributions are seen as contributing factors to success. In the service sector, Baulkham Hills Shire Council (BHSC) was in a debt of \$16 million and they have proved that business excellence is needed to manage an organisation and to make it operate competitively. The result of this commitment is reflected in the sustainable growth in reserves and the unexpected recognition of a bronze medal in its first attempt of participating in the Australian Business Excellence Award. This government sector achieved recognition with no help from external consultants. Their success story is effective management and leadership structure. This just shows that it is very important for top management to be actively involved and supportive in the approach of business excellence. If top management is committed, only then can they set themselves as influential leaders in motivating the rest of the employees in showing dedication to the overall success of the organisation. BizEd Services Private Limited gave an opportunity to its common employees to reward their colleagues who demonstrate positive behaviour in reflecting the organisational values. Leaders in the award winning organisations are not seen as authoritative figures but more like mentors. In the education sector, The Sydney Catholic Education Office has demonstrated outstanding leadership skills and an effective governance process by practicing the principles of Business Excellence. The Sydney Catholic Education Office involves active participation from the whole organisation in achieving the same goals. A well supportive senior management team has enabled it to win the business excellence leadership category award. Their key outstanding factor would be its effective planning strategy of policies. The Sydney Catholic Education Office has aligned the school planning framework with the principles of the Australian Business Excellence Framework. Parents are also involved in planning the strategic planning process and 
their feedbacks are strongly encouraged. This demonstrates a clear sense of direction and purpose. Safety, Community and Environment are also contributing factors to business excellence. This is practised by all the organisations. It makes the organisation more cultured and aware of external factors that can impact the organisation indirectly. ISO 14001 which specifies standards for environmental management policies are crucial in running an organisation.

\subsection{Strategy and Planning}

Employees in BizEd Services are seen as assets in the organisation but not many strategies are implemented to retain the key assets in the organisation. Baulkham Hills Shire Council (BHSC) implements strategies which value its volunteers as assets in the organisation. BHSC aligns the business excellence framework with its strategic planning process. BizEd Services cascades the organisation's values with its individual employee planning process. This reaffirms that excellence is reached only if the organisation understands its business. This can be done through alignment of overall organisational goals with individual objectives in achieving those goals.

\subsection{Knowledge and Information}

All the organisations practice a culture of passing of knowledge and sharing of information within the workforce. The Service Level Agreements (SLAs) ensures that quality is seen as a committed practice of assuring customers of the company's product or service. ISO 9001: 2000 which specifies standards for Quality Management Systems ensures that all product/services conform to the requirements and the needs of customers are documented in the SLAs. Review meetings, auditing and corrective action procedures ensure that improvement is a continuous cycle in the organisation. This proves that accreditation helps the organisation to identify its strengths and weakness in the evaluation process. Doing things right at every stage of the design phase is BizEd Services' strength. This is ensured by the Relationship Managers and through its processes. This shows that a small failure in the process will break the quality chain between BizEd, its clients and the providers.

\subsection{People}

People are seen as a key success factor in making a difference in an organisation. The skills, knowledge and expertise of people are factors that differentiate one organisation from another. In BizEd, employees are accredited to ensure that people with the correct skills are delivering the job. Business Excellence involves every employee in the organisation to be encouraged and committed in making individual contributions to the achi- evement of the overall organisational goals. This teamwork spirit is demonstrated in the formation of crossfunctional teams.BizEd's Services cascades the individual's objectives with the organisational objectives. This process ensures that every employee is accountable for their own performance. This also ensures that employees are motivated to perform well. This process highlights Crosby's point of encouraging individual goals to improve themselves and their teams. This process is also an example of Quality Function Deployment (QFD) which is used to improve quality and customer satisfaction.

Baulkham Hills Shire Council has the Organisational Vitality Survey and the Internal Self Assessment process to encourage employee involvement. New employees also undergo orientation, training and induction program. The mission and the customer service factors are set into targets and measured by all the organisations through the Key Performance Indicators and the Balanced Scorecard approach. These approaches monitor progress and are the written evidence of success for the organisation. The Balanced Scorecard and the self assessment are means of monitoring performance. It is an example of Juran's steps to quality improvement. This just confirms that two way communication and listening are important factors in achieving business excellence. Deming's 14 points which focuses on breaking down barriers is also highlighted by all the organisations through feedbacks, formal and informal meetings and corporate functions. Teamwork which is encouraged by Crosby, Deming and Juran are observed in the quality circle teams, improvement teams and cross functional teams. Crosby's improvement steps which states that improvement teams with representatives from each department is highlighted in the formation of cross functional teams. The Culture Club in BizEd Services and the cross functional teams from Baulkham Hills Shire Council, Water Services Division of Sydney Water Corporation, Chesalon Beecroft Aged Care Services, the Sydney Catholic Education Office, National Library Board of Singapore, Central Provident Fund of Singapore and Qian Hu Private Limited are examples of kaizen teian. It is a Japanese term for implementing suggestion schemes to improve on quality in the organisation. Rewards and recognition program, employees' health and well being are great importance in the organisation. A happy and motivated employee will be enthusiastic in creating a positive work culture.

\subsection{Customer and Market Focus}

Customers can fall under two categories, internal and external. Internal are people working within the organisation and this includes stakeholders and volunteers. Suppliers and other customers fall under the external category. Customer requirements, expectations and specifications are respected and documented. This process is 
implemented in the Service Level Agreements. This Service Level Agreement is a business practise of BHSC, BizEd Services Pte Ltd. and Sydney Water Services Division. Quality control methods are demonstrated when project sponsors and managers in BizEd Services and Sydney Water Services Division deploy its projects according to the requirements of customers. Chesalon Beecroft Aged Care Services demonstrates remarkable strength in building partnership agreement. Chesalon Beecroft Aged Care Services has shown that having an agreement is just not sufficient. The agreement has to be documented and continuously reviewed as quality is all about meeting the requirements and exceeding the expectations of customers. Teamwork plays a major role here in identifying customer and supplier issues and its impact on processes. This proves that effective partnership process creates customer satisfaction and improves business results. Juran's system of carrying out surveys to understand customer needs are also practised by all the organisations. BizEd Services is successful in running its business due to customer satisfaction which leads to customer loyalty. This reflects the reliability of the service. Customers are willing to spend if quality is not compromised and a satisfied customer would definitely recommend and repurchase. This is evident in BizEd Services as it shows that retaining customers cost cheaper than acquiring new customers. Profit per employee is seen in BizEd's business results as long relationships with customers increased profitability. It is also observed that a satisfied customer will be happy to spend more on services. BizEd's business is growing as customers are acquired through referrals from existing customers. BizEd Services introduced its new marketing function team to perform market research techniques, data gathering and analysis to better understand the needs of customers now and in the future. Customer requirements at Water Services Division is met through availability of workers to perform the task, time taken to deliver the service, the reliability of the service and the cost involved in it. The reviewing process ensures that conformance to design and quality assurance is met.

\subsection{Innovation, Quality and Improvement}

The Singapore National Library Board has measured itself against world class standards in library services by focusing their efforts on customers. This transformation was achieved with the help of business excellence. CPF and the NLB have shown that it is important to keep up to date with the technology savvy world. Improved computer technology is used to serve customers. This shows how change has caused technology to replace basic customer service duties. This change is also part of the practise of business excellence. Excellence in service is communicated through more efficient and innovative ways. Just in Time (JIT) is another contributing factor. It is practised by Chesalon Beecroft Aged Care Services in making frequent on time deliveries on small quantities at the right time and place to avoid waste. BHSC has also managed to reduce waste in store due to the implementation of JIT. Assumption busting method is practised in BizEd Services in introducing the "BizEd Mobile" project. A breakthrough in technology leads to a breakthrough performance. This justifies that world class performance is not based on effort alone; creativity and innovation are cornerstones of future success in an organisation. Innovation captures customers. An example of this will be the progressive launch of compact music players over the years. Today, the Ipod Mini has skyrocketed in popularity all over the world. This innovation and creativity in digital music player has increased Apple's total quarterly sales figure by $25 \%$. Water services Division uses IT in deploying its workers to scheduled projects. This shows that utilising resources like knowledge, information and technology helps to understand the long term impact on financial decisions. Sydney Water has opened a trial desalination plant to test and finetune its technologies. The success of this new project will help contribute water supplies to the community after the recent drought condition. These changes reflect the importance of technology in achieving business excellence. It can be seen from emerging markets like China that productivity alone is not sufficient. Manufacturing mass volume of products or demonstrating ordinary service is not the key to win customers and foreign investors. Products with superior quality and extraordinary services are the solution to business results and sustainable growth. This example is reflected in BizEd Services as most of its customers are referred to by its existing customers and NLB's 2.1 million Singaporeans who are members of the public library.

\subsection{Success and Sustainability}

From the results obtained, it can be observed that it is the top management's responsibility to develop cultures that value listening, sharing, learning, creativity and innovation and apply those cultures in practical ways that will produce outstanding results which are sustainable over time. These cultures are aligned with the business excellence framework and the organisational goals. This is achieved by having a clear understanding how its people, process, planning and performance form a big system in the organisation. Such a process ensures that continuous improvement is practised. Previous Australian Business Excellence Award winner, BlueScope Steel has demonstrated long term sustainability by opening a water recycling plant to treat its sewage water to be re-used for industrial purposes. Sydney Water has ensured long term business success and sustainability by recycling effluent 
in its drinking water system.

\subsection{Benchmarks}

New sets of education and healthcare benchmarks can be set from award winners like the Sydney Catholic Education Office and Chesalon Beecroft Aged Care Services respectively. From this study, it can be observed that the framework has made it possible for BHSC's Library facilities to be as competitive as NLB and its aged care services to be as good as Chesalon Beecroft.

\subsection{Understanding Market Trend}

For an organisation to succeed it has to understand market trend and predict future trends from the analysis gathered. For example, mobile phones used to be updated annually but today new models are being launched every quarterly. This is due to the pressure of competition in the consumer world. BizEd Services has set a new marketing function team to analyse current and future market trend. Qian Hu Corporation Ltd. invests in research studies of fishes to remain competitive in its business. The Sydney Catholic Education Office shows that it understands market trend by starting a new leadership program for teachers less than 30 years of age.

\subsection{Value}

Adding value in products and services ensures customer commitment and attracts new customers. Germany's Aldi supermarket is now one of the largest no frill grocer. The key to their success is value. The value added service of Chesalon Beecroft aged care services has enabled it to win the Australian Business Excellence Award. CPF values its customers and this has resulted in the reduced number of customer complaints.

\subsection{Shortcoming}

Shortcoming in all the organisation is observed in the area of risk management. More awareness should be placed on all employees to understand risk issues and the impact of the threat on its organisation. More awareness is also needed to spread the message to all employees and stakeholders about what the organisation is doing in promoting Business Excellence. Water Services Division submitted a report on the Leadership, People and Success and Sustainability Category. The Division only received outstanding recognition for its Success and Sustainability Category. Sydney Water is facing competition from a private company, Services Sydney in providing sewerage services. If Water Services Division manages to spread its Business Excellence practice across the corporation, this issue might no longer be a threat. Water Services Division uses technology to deploy workers to schedule maintenance projects but a recent article on Sydney Morning Herald wrote that more fresh water leaks are found and the damage will take $\$ 8$ billion to replace. Therefore, by adopting the principles of business excellence, Sydney Water Corporation will be able to decide cost effective measures to solve the crisis. They can decide if it is more fruitful to invest in a new technology to fix the leaks or to expand its workforce. Business Excellence seems to be losing its popularity. The number of ISO 9000 certified companies has increased in recent years but the number of organisation participating in Business Excellence has gradually decreased. The government should play an active role in promoting business excellence. Surveys should be carried out to study this analysis.

\section{Conclusions}

The study on Australian Business Excellence Award Winners proves that adopting the principles of business excellence contributes to profitability, market share, productivity, innovation, safety, environmental awareness, organisational and community well being. The framework offers long term success and proved results in the various organisation covered in this thesis. This is reflected in the results achieved by individual case studies. The case studies signify that the approach to quality by using the framework is the same for a Singapore based company or an Australian organisation. The differences are rested upon the approach and deployment of carrying out the measured activities.

Business Excellence begins at the top management level and is then passed down to the organisation in a well-formulated framework. All efforts are directed to the customer's needs as they are the most important person in the business excellence process. Training, empowerment and rewards are important to prepare employees of the challenges of business excellence. Suppliers are also crucial in ensuring the road to business excellence. Quality tools and techniques such as benchmarking are essential in helping everyone in the organisation to practice business excellence. The processes involved in quality are reviewed, audited and improved to ensure a cycle of continuous improvement is practised. All the organisations agree that the reasons for applying for the award is not to gain market advantage and publicity but more as an effort of recognition contributed by everyone in the organisation to achieve quality improvement. The journey of business excellence does not stop at its awards; it is a continuing challenge of improvements and goals. In the research, it was realised that business excellence is losing its popularity. Further research can be concentrated in this area. Further studies can be explored to concentrate on the improved and im- 
plemented changes of the ABE framework and its impact on organisations. Analysing the list of recent award winners, there is a rising trend in the education and health care sector emerging as winners but a decline from the manufacturing sector. An investigation can be conducted in this area too. Further research can be done by monitoring the results achieved by the award winners. Lastly, a study can be conducted to analyse the performance trend of award winners after winning the business excellence award.

\section{Acknowledgements}

The authors wish to acknowledge that an earlier version of the paper was published in the proceedings of the $11^{\text {th }}$ International Conference on ISO 9000 and TQM.

\section{REFERENCES}

[1] A. Ghobadian and H. S. Woo, "Characteristics, Benefits and Shortcomings of Four Major Quality Awards,” International Journal of Quality \& Reliability Management, Vol. 13, No. 2, 1996, pp. 10-44. doi:10.1108/02656719610109999

[2] G. A. Bohoris, "A Comparative Assessment of Some Major Quality Awards,” International Journal of Quality \& Reliability Management, Vol. 12, No. 9, 1995, pp. 3043. doi:10.1108/02656719510101178

[3] J. S. Oakland, “Total Quality Management: Text with Cases,” Taylor \& Francis, 2003.

[4] L. Wallace and K. E. Vallence, "Quality Concepts,” Nelson, South Melbourne,1993

[5] SAI Global, “Autralian Business Excellence Framework,” SAI Global, Australia, 2004.

[6] Mann, R Grigg. N. "A Report on, Engaging Organisations in Business Excellence-An International Study,” Massey University, Palmerston North, 2005.

[7] R. Mann and N. Grigg, "Excellence down under: Reviewing the Australian Business Excellence Framework," Proceedings of 10th International Conference on ISO 9000 and TQM, Shanghai, 2005.

[8] J. D. Wisner and S. G. Eakins, "A Performance Assessment of the US Baldrig Equality Award Winners," International Journal of Quality \& Reliability Management, Vol. 11, No. 2, 1994, pp. 8-25. doi:10.1108/02656719410051643 